Article

\title{
Comparison of the Retrieval of Sea Surface Salinity Using Different Instrument Configurations of MICAP
}

\author{
Lanjie Zhang ${ }^{1,2} \mathbb{1}^{\circ}$, Zhenzhan Wang ${ }^{1, *}$ and Xiaobin Yin ${ }^{3}$ \\ 1 Key Laboratory of Microwave Remote Sensing, National Space Science Center, \\ Chinese Academy of Sciences, Beijing 100190, China; zhanglanjie2012@163.com \\ 2 University of Chinese Academy of Sciences, Beijing 100094, China \\ 3 Beijing Piesat Information Technology Co. Ltd., Beijing 100195, China; yinxiaobin@piesat.cn \\ * Correspondence: wangzhenzhan@mirslab.cn; Tel.: +86-10-6258-6454
}

Received: 25 January 2018; Accepted: 29 March 2018; Published: 4 April 2018

check for updates

\begin{abstract}
The Microwave Imager Combined Active/Passive (MICAP) has been designed to simultaneously retrieve sea surface salinity (SSS), sea surface temperature (SST) and wind speed (WS), and its performance has also been preliminarily analyzed. To determine the influence of the first guess values uncertainties on the retrieved parameters of MICAP, the retrieval accuracies of SSS, SST, and WS are estimated at various noise levels. The results suggest that the errors on the retrieved SSS have not increased dues poorly known initial values of SST and WS, since the MICAP can simultaneously acquire SST information and correct ocean surface roughness. The main objective of this paper is to obtain the simplified instrument configuration of MICAP without loss of the SSS, SST, and WS retrieval accuracies. Comparisons are conducted between three different instrument configurations in retrieval mode, based on the simulation measurements of MICAP. The retrieval results tend to prove that, without the $23.8 \mathrm{GHz}$ channel, the errors on the retrieved SSS, SST, and WS for MICAP could also satisfy the accuracy requirements well globally during only one satellite pass. By contrast, without the $1.26 \mathrm{GHz}$ scatterometer, there are relatively large increases in the SSS, SST, and WS errors at middle/low latitudes.
\end{abstract}

Keywords: MICAP; forward model; combined active/passive SSS retrieval algorithm; different instrument configurations; retrieval errors

\section{Introduction}

At a given pressure, the salinity and temperature determine the density of sea water so that the salinity plays an important role in the formation and circulation of water masses [1,2]. The SSS is also a key variable for understanding the role of the fresh water input and output in ocean dynamics [3]. The variations of the water cycle can be directly monitored by tracking SSS [4,5]. Knowledge of the distribution of SSS is key to understanding how the water cycle affects the ocean circulation and the climate variability [6]. In addition, knowledge of the distribution of SSS is also important for providing valuable estimations of rainfall over the oceans through its link to the evaporation-precipitation balance $[6,7]$. Although the full deployment of the Agro profiling float array expands the in situ observing system of SSS, the in situ sample density of SSS is still sparse in both time and space [8,9]. For the past ten years, with the successful launch of the Soil Moisture and Ocean Salinity (SMOS) mission, the Aquarius/SAC-D mission and the Soil Moisture Active-Passive (SMAP) mission, satellite SSS has become a reality. These three missions can systematically map SSS over all areas of the open ocean except near land and ice boundaries [8], and offer complementary information to existing in situ measurements $[8,10]$. 
The sensitivity of brightness temperature (TB) to SSS remains high only in the low frequency ( $1 \mathrm{GHz}, \mathrm{L}-\mathrm{band})$, and the L-band is also protected against human-made emissions [11,12]. Thus, L-band frequency range has been chosen for SMOS, Aquarius and SMAP missions. The unique payload of SMOS, L-band Microwave Imaging Radiometer using two-dimensional Aperture Synthesis, is a fully polarimetric radiometer (with an optional dual polarized mode), and it has multi-angular imaging capability $[11,13]$. Different from SMOS, Aquarius includes an L-band radiometer with a larger size real aperture antenna and an integrated L-band scatterometer to measure simultaneous oceanic backscatter [14]. The SMAP mission also originally utilized combined passive/active microwave instruments. However, the radar of SMAP ceased transmission on July 2015, and only the radiometer of SMAP still operates continuously over the ocean to provide SSS observations [15]. The SSS maps at 150-200 km, one-month resolution with an accuracy of $\sim 0.2 \mathrm{psu}$ or better at an open ocean are basically achieved by the above three missions $[10,16,17]$.

Although SMOS, Aquarius, and SMAP have provided abundant global SSS measurements with adequate resolution and coverage, it is still a challenge to achieve higher retrieval accuracy of SSS from the observations of these satellites. Moreover, research on seasonal and interannual variations of SSS in near-coastal and middle/high latitudes is relatively limited due to the low-quality satellite-derived SSS measurements in these regions [18], reinforcing the requirement for accurate SSS measurements to possibly capture the seasonal and interannual variations of SSS. Developing a new payload to obtain high-quality global observations of SSS is necessary. Thus, the payload MICAP of the Ocean Salinity Satellite mission is designed. MICAP is dedicated to "all-weather" estimate the SSS at high spatial resolution. At L-band, TB not only depends on SSS, but also depends on SST, and sea roughness, which is the main geophysical error source in the retrieval of SSS from L-band TB [19]. Yueh et al. found that the impact of wind on the retrieved SSS is equivalent to several psu [20]. Thus, an L-band scatterometer is included in the MICAP to correct sea surface roughness.

The goal of MICAP is to produce SSS with an accuracy of 1 psu during one satellite pass, and provide the science community with monthly averaged SSS maps at a $200 \mathrm{~km}$ spatial scale over the open ocean to an accuracy of $\sim 0.1 \mathrm{psu}$. In our previous studies, we have analyzed the preliminary performance (potentials and limitations) of MICAP using a combined active/passive SSS retrieval algorithm [21]. Result indicate that the SSS, SST, and WS errors with the original configuration of MICAP can satisfy the accuracy requirements. In this study, the influence of the first guess values uncertainties on the retrieved parameters is estimated at various noise levels. In addition, to obtain the simplified configuration of MICAP, the retrieval accuracies of SSS, SST, and WS with different instrument configurations are mainly studied.

Datasets and forward models are presented in Section 2. The instrument characteristics and simulation method of measurements are described in Section 3. Then, the combined active/passive SSS retrieval algorithm is introduced. To obtain the simplified instrument configuration of MICAP for SSS, SST, and WS retrieval, different channel combinations are given in Section 4. Finally, the retrieval accuracies of SSS, SST, and WS are evaluated using a simulated database (Section 5). Conclusions are provided in Section 6.

\section{Datasets and Model}

\subsection{Datasets}

The initialized oceanic and atmospheric inputs, which are used to simulate the sea surface TBs and backscatter coefficient in the following section, include three datasets: the monthly averaged grid data of the In Situ Analysis System (ISAS), the Advanced Microwave Scanning Radiometer 2 (AMSR-2) and the WindSat.

Specifically, the monthly reanalysis of SSS maps of the ISAS product by Laboratoire de Physique des Océans is used. These SSS maps preserve as much as possible the time and space sampling capabilities of the Argo network of profiling floats [22]. In general, the first layer of the monthly salinity 
data of ISAS is used to represent the SSS measurements [5]. These data are downloaded from the website (http:/ / www.seanoe.org/data/00348/45945/). From $77^{\circ} \mathrm{S}$ to $66.5^{\circ} \mathrm{N}$, the latitude grid of SSS of ISAS is 0.5 degree Mercator, where it is thus isotropic with a resolution that increases with latitude. From $66.5^{\circ}$ to North Pole, the latitude step is fixed. Different from the latitude, from $180^{\circ} \mathrm{W}$ to $180^{\circ} \mathrm{E}$, the longitude grid of SSS of ISAS is fixed ( 0.5 degree). To unify the spatial resolution of the above three datasets, the SSS map of ISAS in August 2012 is interpolated to $0.25^{\circ} \times 0.25^{\circ}$ grid (approximately $25 \mathrm{~km}$ grid) using a bilinear interpolation method.

To simulate sea surface TBs, the monthly averaged SST, WS, and atmospheric products also need to be used apart from SSS field. Thus, the monthly averaged SST, WS, vapor (V), and cloud liquid (L) products of AMSR-2 in August 2012 provided by Remote Sensing Systems (RSS) [23] are used, which all are organized on the $0.25 \times 0.25$ degree grid. Because the monthly averaged products of AMSR- 2 are produced by averaging of all data within the calendar month, the specific time information is not contained in these data products. To simulate the backscatter, the monthly averaged wind direction (WD) product of WindSat in August 2012 obtained from RSS [24] is also used. This WD product available on RSS are created by simple bin resampling to a 0.25 degree Earth grid, and it also does not contain specific time information. All these data from RSS are downloaded from the website (http:/ / www.remss.com/). Note that the data values of SST, WS, V, L, and WD from RSS fall between 0 and 255 in their respective data file. These data values between 0 and 250 need to be scaled to obtain meaningful geophysical units before being used. To scale the data, multiply by the scale factors (and add the offsets) specifically listed in the website of RSS. In addition, the first guess values for those variables (SSS, SST, WS, WD, V, and L) used in the inversion also come from the above datasets.

\subsection{Forward Models of $L / C / K$ Band Radiometers}

The forward models are used to calculate the TB that reaches radiometer antennas from the emitting top ocean layer [25]. The TBs comprise of the flat sea emission plus the rough sea surface component, atmospheric upwelling radiation and downwelling radiation scattered by the rough sea surface as well as atmospheric absorption, and the galactic noise being scattered on the roughened surface $[25,26]$. At polarization $p$, sea surface TB at the top of the atmosphere can be calculated by [27]:

$$
T B_{p}=T b_{u p}+e^{-\tau_{a t m}}\left(T b_{p, f l a t}+T b_{p, w i n d}+T b_{\text {down }} \Gamma_{p}+T_{\text {galref }}\right),
$$

where $p$ represents the vertical polarization (V-pol.) and horizontal polarization (H-pol.), $T b_{u p}$ represents the upwelling atmospheric self-emitted direct to the antenna, $e^{-\tau_{\text {atm }}}$ represents the equivalent optical thickness of the atmosphere, $T b_{p}$,flat denotes the $T B$ of a flat sea surface, $T b_{p}$,wind is the wind-induced contribution sea surface $T B, T b_{\text {down }}$ denotes the self-emitted of $T B$ by the atmospheric downward and attenuated along the downward path, $\Gamma_{p}$ is the reflection coefficient of the sea surface, which is computed as $1-\left(T b_{p \text {,flat }}+T b_{p \text {,wind }}\right) / S S T$, and $T b_{\text {galref }}$ is the contribution of cosmic and galactic radiation which is already scattered by the sea surface. In the following, we show the specific models which are used in this study.

Meissner et al. indicated that the uncertainty between TB (in Kelvin) and sea surface salinity (in psu) is approximately 1:2 [28]. Thus, the accuracy of TB calculated models directly affects the retrieval accuracy of SSS [29]. Here, to better understand the influence of the dielectric constant model on the TB of a flat sea surface, Figure 1 shows the differences of L-band TBs in August 2012 calculated by Klein and Swift (KS) model (1977) [30], Meissner and Wentz (MW) model (2012) [31] and Yiwen Zhou et al. (GW) model (2017) [32] based on the datasets in Section 2.1. The incident angle is chosen as $30^{\circ}$ which is approximately the incident angle for the inner-most beam on the Aquarius. The mean bias (standard deviation) between the TB with GW model and TB with KS model are $-0.10 \mathrm{~K}(1.22 \mathrm{~K})$ at H-pol., and $-0.12 \mathrm{~K}(1.47 \mathrm{~K})$ at V-pol.. The mean bias (standard deviation) between the TB with GW model and TB with MW model are $-0.26 \mathrm{~K}(1.22 \mathrm{~K})$ at $\mathrm{H}$-pol., and $-0.31 \mathrm{~K}(1.47 \mathrm{~K})$ at V-pol.. It is worth noting that the bias between GW and MW is higher than that between GW and KS at middle/high 
latitudes. The results indicate that the TB will be affected by the dielectric constant model, and further the error on the retrieved SSS will also be affected.

(a) $\mathrm{TH}_{\mathrm{L}}$, mean $=-0.10(\mathrm{~K}), \mathrm{std}=1.22(\mathrm{~K})$

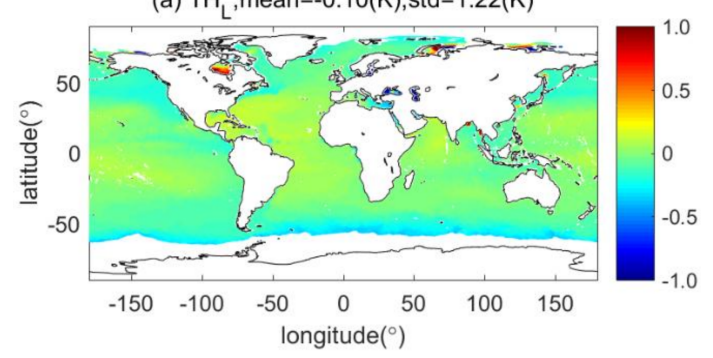

(c) $\mathrm{TH}_{\mathrm{L}}$, mean $=-0.26(\mathrm{~K}), \mathrm{std}=1.22(\mathrm{~K})$

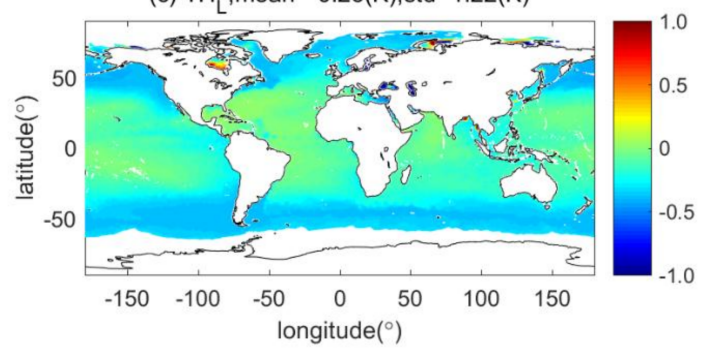

(b) $\mathrm{TV}_{\mathrm{L}}$, mean=-0.12(K), std=1.47(K)

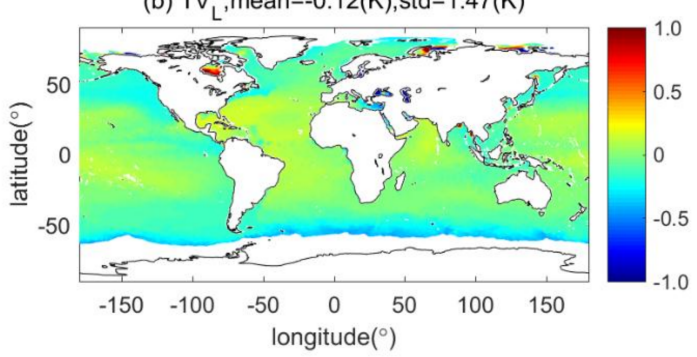

(d) $\mathrm{TV}_{\mathrm{L}}$, mean $=-0.31(\mathrm{~K}), \mathrm{std}=1.47(\mathrm{~K})$

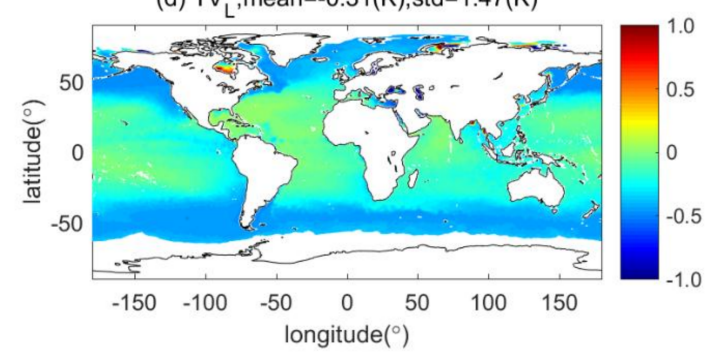

Figure 1. The difference of the TB of flat sea surface with KS, MW and GW dielectric constant models. This is an example of the differences are averaged over one month (August 2012) and in $0.25^{\circ}$ bin in longitude and latitude: $(\mathbf{a}, \mathbf{b})$ the difference between GW and $\mathrm{KS}$ models at $30^{\circ}$ incident angle for $\mathrm{H}$-pol. and V-pol., respectively; and (c,d) the difference between GW and MW models at $30^{\circ}$ incident angle for H-pol. and V-pol., respectively.

In this study, the choice of dielectric constant model is not critical since we are working only with simulated data. Thus, we chose the KS model to calculate the TBs of a flat sea surface. The two-scale model of SMOS from ESA Level 2 Ocean Salinity Processor (L2OSP) is used as the TB model of L-band radiometer [33,34]. The model function from Meissner and Wentz (2012) is used as TB model of C and $\mathrm{K}$ band radiometers [31]. Other contributions from atmospheric emission and absorption of L-band and C/K band are calculated by Liebe et al. (1993) [35] and Wentz et al. (2000) atmosphere models [36], respectively.

\subsection{Backscatter Coefficient Model of L-Band Scatterometer}

The backscatter coefficient is usually calculated by the theoretical model and the empirical model (also known as the geophysical model function). Currently, for L band, the major domestic and international geophysical model function (GMF) is derived from the scatterometer data of Aquarius and the synthetic aperture radar data of Phased Array type L-band Synthetic Aperture Radar (PALSAR). The GMF relates the microwave backscatter to the wind speed and direction, and is generally expressed as:

$$
\sigma_{0}=A_{0}(w, \theta)+A_{1}(w, \theta) \cos \varphi+A_{2}(w, \theta) \cos 2 \varphi,
$$

where $\sigma_{0}$ denotes the backscatter coefficient, $A_{n}(w, \varphi)(n=0,1,2)$ is a function of the WS $w$ and incident angle $\theta$, and $\varphi$ denotes the relative WD. Based on the GMF of PALSAR [37] and Aquarius (Meissner et al.) [28], the backscatter coefficients versus WD and $10 \mathrm{~m} / \mathrm{s}$ wind speed for $\mathrm{HH}$ and VV polarizations are calculated in Figure 2. The incident angles are chosen as $29.36^{\circ}, 39.44^{\circ}$ and $46.29^{\circ}$, which are approximately the incident angles for the three beams on the Aquarius. 


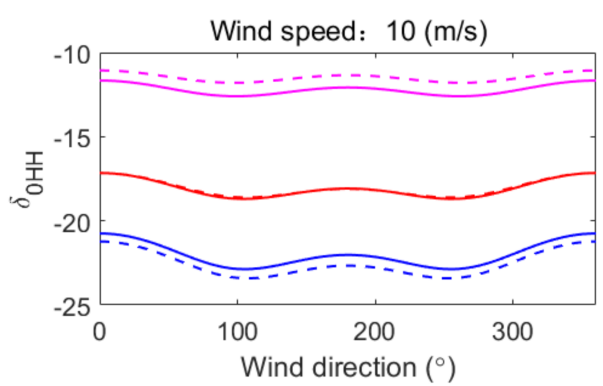

(a) HH polarization

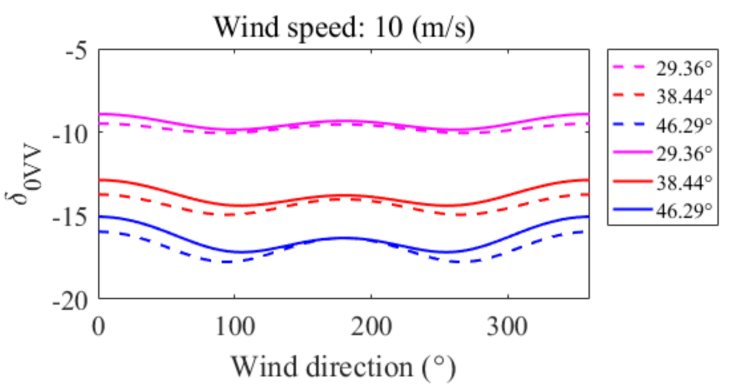

(b) VV polarization

Figure 2. Comparison of WD dependence of the backscatter coefficient for: HH polarization (a); and VV polarization (b), using GMF of Isoguchi and Shimada for PALSAR (solid line) and Meissner et al. (2014) for Aquarius (dashed line) at $10 \mathrm{~m} / \mathrm{s}$. The incident angles are chosen as $29.36^{\circ}$ (mauve), $39.44^{\circ}$ (red) and $46.29^{\circ}$ (blue).

Figure 2 shows that the WD dependence of backscatter coefficient for the GMFs of PALSAR and Aquarius are almost the same, especially for $\mathrm{HH}$ polarization. The amplitude changes are less than $1 \mathrm{~dB}$ for each incident angle. Particularly, for the $46.29^{\circ}$ incident angle, in which the backscatter coefficient is calculated with the GMF of PALSAR using the extrapolate method, there is a similar trend for WD dependence of backscatter coefficient to other incident angles. In this study, the GMF from PALSAR is used as the GMF of L-band scatterometer, since the incident angle range of MICAP $\left(30^{\circ}-55^{\circ}\right)$ is approximate to that of PALSAR $\left(17^{\circ}-43^{\circ}\right)$ compared with Aquarius $\left(29.36^{\circ}, 39.44^{\circ}\right.$ and $\left.46.29^{\circ}\right)$. For the large incident angles $\left(43^{\circ}-55^{\circ}\right)$, the extrapolation method is used to calculate the backscatter coefficient of MICAP.

\section{Description of MICAP}

\subsection{Instrument Characteristics}

The MICAP will be one of the payloads for Ocean Salinity Satellite mission. It uses one-dimensional microwave interferometric radiometers that operates at $1.4 \mathrm{GHz}, 6.9 \mathrm{GHz}, 18.7 \mathrm{GHz}$ and $23.8 \mathrm{GHz}$ (abbreviated as MIR in the following) combined with a digital beam forming scatterometer at $1.26 \mathrm{GHz}$ (abbreviated as DBFS in the following) to monitor SSS and reduce geophysical errors caused by surface roughness and SST in the original design. Compared with the two-dimensional microwave interferometric radiometer of SMOS, the one-dimensional MIR of MICAP has lower complexity. Compared with the real aperture radiometer of Aquarius, the MICAP can achieve better spatial resolution and wider swath using one-dimensional MIR [38]. In addition, combined the MIR with DBFS, MICAP can achieve simultaneous remote sensing of the SSS, SST, and WS. The detailed system architectures of MICAP are given in [38]. The main specifications of MICAP are summarized in Table 1 [38].

Table 1. The main system specifications of MICAP.

\begin{tabular}{|c|c|c|c|c|}
\hline Instruments & L-Band Radiometer & C-Band Radiometer & K-Band Radiometer & L-Band Scatterometer \\
\hline frequency & $1.4 \mathrm{GHz}$ & $6.9 \mathrm{GHz}$ & $18.7 \mathrm{GHz}, 23.8^{1} \mathrm{GHz}$ & $1.26 \mathrm{GHz}$ \\
\hline sensitivity & $0.1 \mathrm{~K}$ & $0.3 \mathrm{~K}$ & $0.3 \mathrm{~K}$ & $0.1 \mathrm{~dB}$ \\
\hline polarization & $\mathrm{H}, \mathrm{V}, \mathrm{T} 3$ & $\mathrm{H}, \mathrm{V}$, & $\mathrm{H}, \mathrm{V}$, & $\mathrm{HH}, \mathrm{HV}, \mathrm{VV}, \mathrm{VH}$ \\
\hline incident angle & \multicolumn{4}{|c|}{$30-55^{\circ}$} \\
\hline spatial resolution & \multirow{4}{*}{\multicolumn{4}{|c|}{$\begin{array}{c}\text { along-track: } 65 / 15 / 15 \mathrm{~km} \text {; cross-track: } 50-100 \mathrm{~km} \\
\begin{aligned} \text { Reflector: } 3.0 \mathrm{~m} \times 5.5 \mathrm{~m} \text { (after deployment), Feed array: } 4 \mathrm{~m} \times 0.5 \mathrm{~m} \\
>1000 \mathrm{~km} \\
3 \text { days }\end{aligned}\end{array}$}} \\
\hline antenna size & & & & \\
\hline FOV & & & & \\
\hline revisit & & & & \\
\hline SSS accuracy & \multicolumn{4}{|c|}{$<1$ psu, over one satellite pass; < 0.1 psu, over $200 \mathrm{~km}$ and 30 days } \\
\hline
\end{tabular}

${ }^{1}$ The $23.8 \mathrm{GHz}$ of K-band radiometer of MICAP is a candidate channel, and whether to keep this frequency is now under consideration. 


\subsection{Simulate TBs and Backscatter of MICAP}

Because the MICAP is not launched yet, it is necessary to simulate TBs and backscatter as would be measured by MICAP using forward models and GMF as well as the initialized oceanic and atmospheric inputs (SSS, SST, WS, WD, V and L) in Section 2. An illustration of the simplified flow chart of the simulation process is displayed in Figure 3.

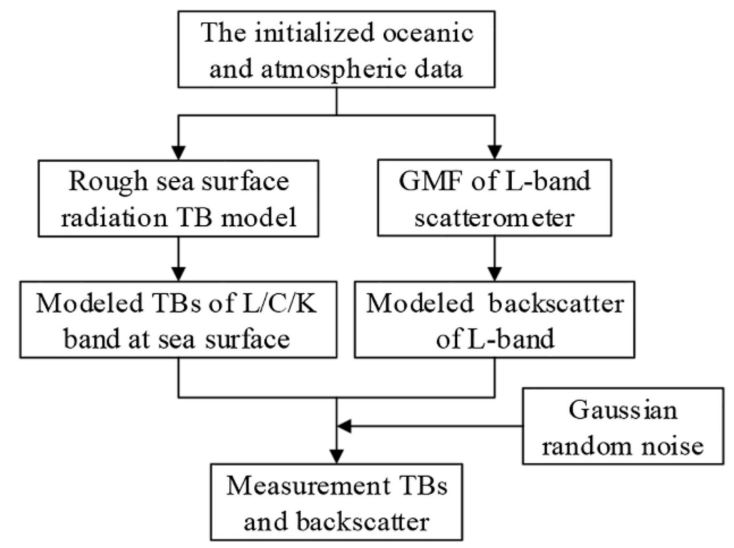

Figure 3. The simplified flow chart of the simulation process for measurements of MICAP.

Based on Figure 3 and the following three assumptions, TBs and backscatter of the MICAP can be produced: (1) in all directions, the ocean-atmosphere parameters of each grid point are homogeneous at $30^{\circ}$ to $55^{\circ}$ incident angles ( $\pm 500 \mathrm{~km}$ swath); (2) all of the differences between measurements (TB/backscatter) and modeling values provided by model functions in Section 2 are regarded as measurement noises, and these noises are Gaussian; and (3) the measurement data (TB/backscatter) are generated by adding Gaussian random noises, which are related to the instrument sensitivities and incident angles of MICAP in the Table I, to TB and backscatter that are predicted by the above mentioned forward models (Section 2.2) and GMF (Section 2.3), respectively, and then repeated 2000 times.

\section{Algorithm and Configurations}

\subsection{Combined Active/Passive SSS Retrieval Algorithm}

Based on the SSS retrieval algorithm of SMOS and JPLCAP v4.0 of Aquarius, the active/passive SSS retrieval algorithm of MICAP is proposed. It retrieves SSS, SST, and WS simultaneously by finding the best fit solution to minimize a cost function (weighted sum of square differences between MICAP measurements and forward models). In addition, we add five additional terms in the cost function to constrain the SSS, SST, and WS solutions. The cost function of MICAP can be expressed as the following form:

$$
\chi^{2}=\sum_{p=V, H} \frac{\left(T_{B p f}-T_{B p m f}\right)^{2}}{\Delta T_{p f}^{2}}+\sum_{p=V, H} \frac{\left(\sigma_{0 p}-\sigma_{0 p m}\right)^{2}}{\left(\gamma_{p} \sigma_{0 p}\right)^{2}}+\sum_{i=1}^{M} \frac{\left[P_{i}-P_{i a}\right]^{2}}{\Delta P^{2}},
$$

where $V$ and $H$ represent the V-pol. and H-pol.; the $T B_{p f}$ represent the measured TBs of multi-incident angles at 1.4, 6.9, 18.7 and $23.8 \mathrm{GHz} ; \mathrm{TB}_{p m f}$ is the simulated TB of the forward model at the above four frequencies; $\sigma_{0 p}$ and $\sigma_{0 p m}$ are the measured and simulated backscatter at $1.26 \mathrm{GHz}$, respectively; $M$ is the number of the parameters; $P_{i}$ consists of the parameters that may influence the modeled TBs, including SSS, SST, WS, WD, V, and L; the subscript $a$ denote the initial fields of variables; the value 
of $\Delta$ is the weighting factors, which relate to the respective variance of expected error initial fields of variables; and $\Delta T_{p f}$ and $\gamma_{p}$ relate to the instrument sensitivities in Table 1.

Once the TBs and backscatter are simulated, as described in Section 3.2, which correspond the MICAP measurements, the SSS, SST, and WS can be simultaneously retrieved using the combined active/passive SSS retrieval algorithm. During the inversion, the first guess geophysical inputs, i.e., SSS, SST, WS, WD, V, and L, are adjusted to minimize the cost function (Equation (3)).

\subsection{Different Instrument Configurations of MICAP}

As shown before, the $1.4 \mathrm{GHz}$ provides a good sensitivity to the SSS over a large range. However, even in this frequency, the sensitivity of TB to SSS remains low due to the uncertainty on the TB variation related to the surface roughness and SST. Thus, the L-band scattrometer and C/K band radiometers are also included into the original instrument design of MICAP except L-band radiometer (default configuration). In this study, to obtain the simplified instrument configuration of MICAP that can provide SSS, SST, and WS retrieval with the required characteristics using the least frequency bands, three different instrument configuration selections (Table 2) in retrieval mode are compared.

Table 2. The different instrument configuration selections.

\begin{tabular}{cc}
\hline Number & Configurations \\
\hline No. 1 & $1.26 \mathrm{GHz}, 1.4 \mathrm{GHz}, 6.9 \mathrm{GHz}, 18.7 \mathrm{GHz}$ and $23.8 \mathrm{GHz}$ (default) \\
No. 2 & without $1.26 \mathrm{GHz}$ scatterometer \\
No. 3 & without $23.8 \mathrm{GHz}$ \\
\hline
\end{tabular}

Because the retrieval accuracies of SSS, SST, and WS may be affected by the polarization modes of instruments, except for the different instrument configurations listed in Table 2, polarization selections in retrieval mode are also tested, such as with all MICAP frequencies except the H-pol. of $23.8 \mathrm{GHz}$. In this study, we ignore the effect of different polarization selections on the SSS, SST, and WS retrieval accuracies, and focus only on the effect of different instrument configurations, as shown in Table 2.

\section{Results}

\subsection{The Retrieval Results at Single Pixel}

In this section, the root mean square (RMS) errors on the retrieved SSS, SST, and WS at the single pixel with No. 1 configuration in Table 2 are estimated. The average of their RMS errors for seven homogeneous scenes specified in Table 3 is shown in Table 4. As can be seen, the smallest RMS errors are obtained for the scene having high SST and low WS, where the sensitivity of TB to SSS and WS is high. The RMS errors for low SST scenes are higher than those for high SST scenes due to the lower sensitivity of TB to SSS, SST, and WS at low SST. The RMS errors are smaller at $3 \mathrm{~m} / \mathrm{s}$ than those obtained at $7 \mathrm{~m} / \mathrm{s}$. The smaller error is explained by the greater sensitivity of TB to SSS, SST and WS at low WS. In addition, the greatest SSS and WS RMS errors (1.22 psu) are obtained for low SST and low SSS scenes. The greatest SST RMS error is obtained for low SST scenes $\left(1.54{ }^{\circ} \mathrm{C}\right)$.

Table 3. The seven homogeneous scenes used in the retrievals.

\begin{tabular}{cccc}
\hline Scene & SSS (psu) & SST $\left({ }^{\circ} \mathbf{C}\right)$ & WS $(\mathbf{m} / \mathbf{s})$ \\
\hline Reference & 35 & 15 & 7 \\
High SST & 35 & 25 & 7 \\
High SST and SSS & 38 & 25 & 7 \\
High SST, Low WS & 35 & 25 & 3 \\
Low SST & 35 & 5 & 7 \\
Low SST and SSS & 33 & 5 & 7 \\
Low SST and WS & 35 & 5 & 3 \\
\hline
\end{tabular}


Table 4. The average errors of SSS, SST, and WS from $30^{\circ}$ to $55^{\circ}$ incident angles for the seven scenes in Table 3.

\begin{tabular}{cccc}
\hline Scene & SSS (psu) & SST $\left({ }^{\circ} \mathbf{C}\right)$ & WS $(\mathbf{m} / \mathbf{s})$ \\
\hline Reference & 0.64 & 1.19 & 0.68 \\
High SST & 0.52 & 1.12 & 0.68 \\
High SST and SSS & 0.57 & 1.13 & 0.76 \\
High SST, Low WS & 0.49 & 1.00 & 0.46 \\
Low SST & 1.17 & 1.54 & 0.78 \\
Low SST and SSS & 1.22 & 1.50 & 0.79 \\
Low SST and WS & 1.10 & 1.44 & 0.50 \\
\hline
\end{tabular}

Further, the SSS, SST, and WS RMS errors are tested for various noise levels on first guess values (Table 5), under the reference scene (Table 3). It is obvious that SSS RMS error is almost invariable regardless of whether there is noise on the first guess values for SST and WS. The greatest SSS RMS error ( $0.82 \mathrm{psu})$ is obtained only for poorly known SSS, increasing about $0.2 \mathrm{psu}$ which is lower than the standard deviation (std) of the noise on the SSS first guess values $(0.5 \mathrm{psu})$. It indicates that the SSS RMS error of MICAP is only weakly sensitive to the uncertainties of the first guess values for SST and WS. In addition, the greatest SST $\left(2.24{ }^{\circ} \mathrm{C}\right)$ and WS $(2.03 \mathrm{~m} / \mathrm{s})$ RMS errors are also obtained for poorly known SST and WS, respectively. The abovementioned results indicate that the errors on the retrieved SSS, SST, and WS of MICAP depend primarily upon the noise added to each first guess values at $15^{\circ} \mathrm{C}$, which may be because the MICAP can achieve simultaneous remote sensing of SSS, SST, and WS.

Table 5. The average RMS errors of SSS, SST, and WS from $30^{\circ}$ to $55^{\circ}$ incident angles for the various levels of noise. $\sigma_{\mathrm{sss}}, \sigma_{\mathrm{sst}}$, and $\sigma_{\mathrm{ws}}$ represent the std of the noise on the first guess values for SSS, SST, and WS, respectively.

\begin{tabular}{cccc}
\hline Scene & SSS (psu) & SST $\left({ }^{\circ} \mathbf{C}\right)$ & WS (m/s) \\
\hline Reference & 0.64 & 1.19 & 0.68 \\
$\sigma_{\text {sss }}=0.5$ & 0.82 & 1.19 & 0.68 \\
$\sigma_{\text {sst }}=1$ & 0.64 & 1.50 & 0.68 \\
$\sigma_{\text {sst }}=2$ & 0.64 & 2.24 & 0.68 \\
$\sigma_{\text {ws }}=1$ & 0.64 & 1.19 & 1.10 \\
$\sigma_{\text {ws }}=2$ & 0.64 & 1.19 & 2.03 \\
\hline
\end{tabular}

\subsection{Comparison of Retrieval Results with Different Configurations Over the Globe}

\subsubsection{Default Configuration and without $23.8 \mathrm{GHz}$}

To assess whether $23.8 \mathrm{GHz}$ channel is necessary to provide SSS retrieval with the required characteristics of MICAP, the SSS RMS errors during only one satellite pass with No. 1 and No. 3 configurations are shown in Figure $4 \mathrm{a}, \mathrm{b}$, respectively. It shows that the SSS RMS error is below $1 \mathrm{psu}$ and varies around $0.61 \mathrm{psu}$ at most of the middle/low latitudes (from $50^{\circ} \mathrm{S}$ to $45^{\circ} \mathrm{N}$ ). The smallest SSS RMS error is obtained in regions of low wind speed and high temperature because the sensitivities of TB to WS at low WS and TB to SSS at high SST are greater. The SSS RMS errors increase with latitude in the Southern/ Northern Hemisphere is primarily due to the increase of WS and the decrease of SST. The greatest SSS RMS error (achieve or exceed $1 \mathrm{psu}$ ) is obtained at high latitudes for which the sensitivity of TB to SSS is lower at cold SST values. Compared to No. 1 configuration, the SSS RMS errors with No. 3 increase only slightly for most of the middle/low latitudes. Especially near the equator and in the Southern Hemisphere, the SSS RMS errors with No. 3 are almost consistent with No. 1, which indicates that $23.8 \mathrm{GHz}$ channels (H-pol. and V-pol.) of MICAP may not bring much information in terms of SSS. 
(a) No.1 SSS RMS error (psu)

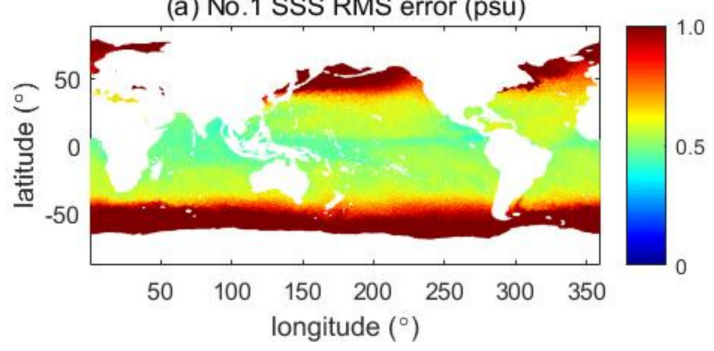

(c) No.1 SST RMS error (psu)

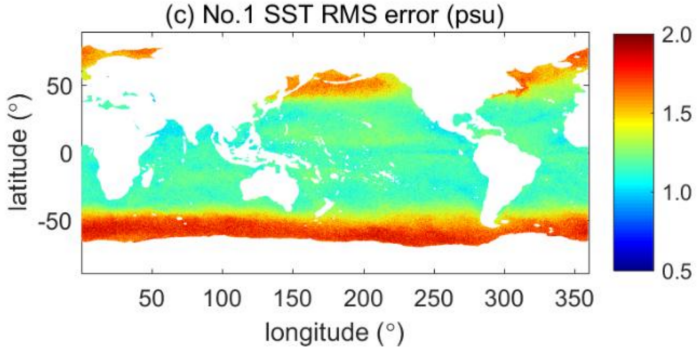

(e) No.1 WS RMS error (psu)

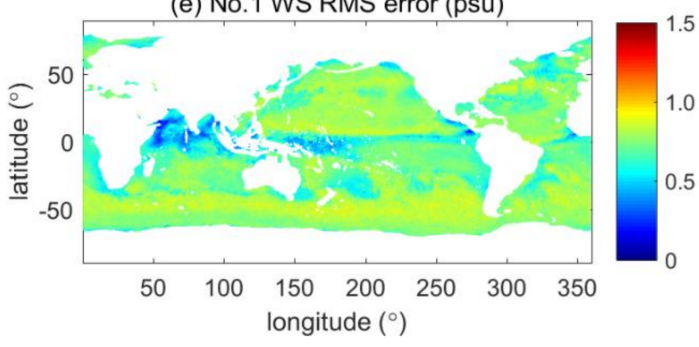

(b) No.3 SSS RMS error (psu)

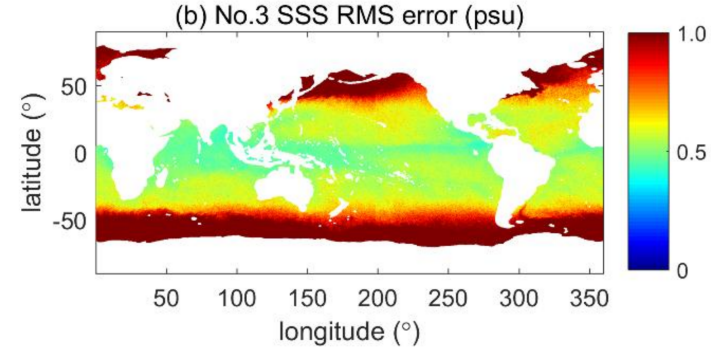

(d) No.3 SST RMS error (psu)

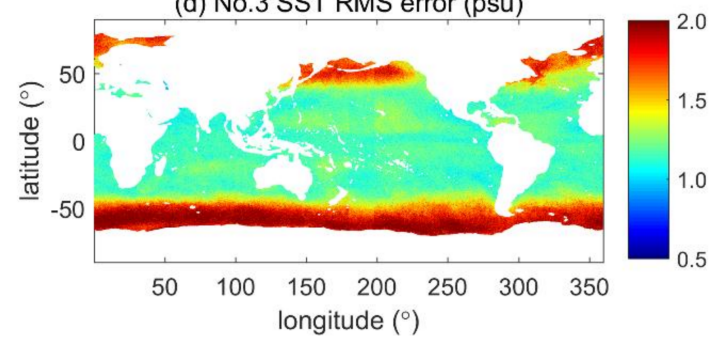

(f) No.3 WS RMS error (psu)

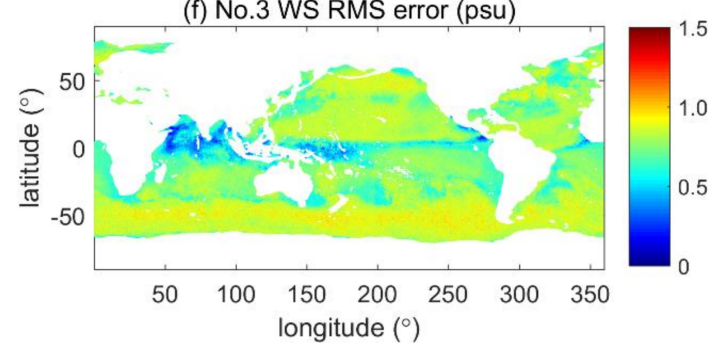

Figure 4. The errors on the retrieved SSS, SST, and WS with default configuration and with default configuration except $23.8 \mathrm{GHz}$ of MICAP during only one satellite pass: SSS (a); SST (c); and WS (e) errors with No. 1 configuration; and SSS (b); SST (d); and WS (f) errors with No. 3 configuration.

Figure 4c,d shows the SST RMS error with No. 1 and No. 3 configurations, respectively. The SST RMS errors vary around $1.15^{\circ} \mathrm{C}$ at most of the middle/low latitudes, and they slightly increase at high WS. At high latitude, a significant change of the SST RMS errors is observed because of the low sensitivity of TB to cold SST values. The smallest SST RMS error is obtained near the equator because of the greater sensitivity of TB to high SST. In the Northern Hemisphere where SST is higher, the SST RMS errors are slightly lower than those in the Southern Hemisphere at equivalent latitude. Compared with No. 1 configuration, the SST RMS errors with No. 3 also increase slightly for most of the middle/low latitudes.

The WS RMS errors with No. 1 and No. 3 configurations are presented in Figure 4e,f, respectively. At middle/low latitudes, the WS RMS errors vary around $0.75 \mathrm{~m} / \mathrm{s}$. The smallest WS RMS errors are observed in regions of low wind speed because the sensitivity of TB to WS is higher than at moderate wind speeds. Near the Arabian Sea, the Bay of Bengal and the equator (the wind speed is around $3 \mathrm{~m} / \mathrm{s}$ ), the WS RMS error is lower than $0.5 \mathrm{~m} / \mathrm{s}$. A greater increase in WS RMS error is observed from the equator to $10^{\circ} \mathrm{N} / \mathrm{S}$ because the WS increases quickly with the increasing latitude. The differences of WS RMS errors between No. 3 and No. 1 configurations are greater for most of the middle/low latitudes compared with SSS and SST.

Figure 4 indicates that $23.8 \mathrm{GHz}$ channels (H-pol. and V-pol.) do not bring much information for the SSS, SST, and WS retrieval accuracy of MICAP at the pixel level. This is explained by the weak sensitivity of SSS, SST, and WS RMS errors to the atmospheric parameters (V and L) except for low SST. It is proven that a simple instrument configuration of MICAP without $23.8 \mathrm{GHz}$ could satisfy the accuracy requirements well in terms of SSS over the globe during only one satellite pass. 


\subsubsection{Default Configuration and Without Scatterometer}

To estimate the impact of the $1.26 \mathrm{GHz}$ scatterometer, which is used to simultaneously correct surface roughness, on the MICAP retrieved parameters, the SSS, SST, and WS RMS errors with No. 1 and No. 2 configurations are shown in Figure 5. For No. 2 configuration, the SSS RMS errors (Figure $5 \mathrm{~b}$ ) are below 1 psu at most of the middle/low latitudes (from $49^{\circ} \mathrm{S}$ to $40^{\circ} \mathrm{N}$ ), and they vary around $0.7 \mathrm{psu}$. Compared with No. 1 configuration, the SSS RMS errors with No. 2 increase significantly at the middle/low latitudes, especially for high WS. The result emphasizes the larger dependence of the SSS error to roughness parameter. In the high latitude, the SSS RMS errors increase slightly with the increasing WS. It is explained that the impact of the roughness parameter on the SSS RMS error will decrease at low SST (below about $7{ }^{\circ} \mathrm{C}$ ). In the Northern Hemispheres, SST is warmer where the sensitivity of TB to SSS is higher. Thus, the SSS RMS errors at equivalent latitude are slightly smaller than those in the Southern Hemisphere.

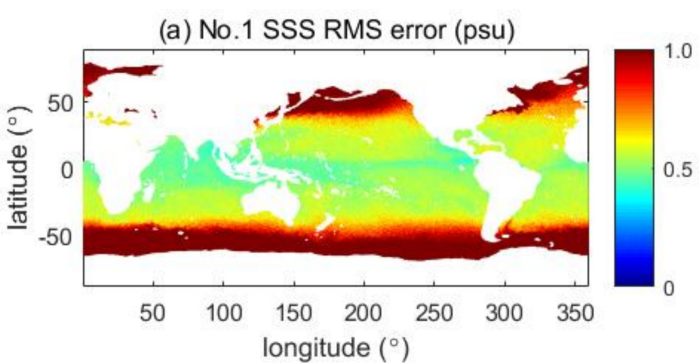

(c) No.1 SST RMS error (psu)

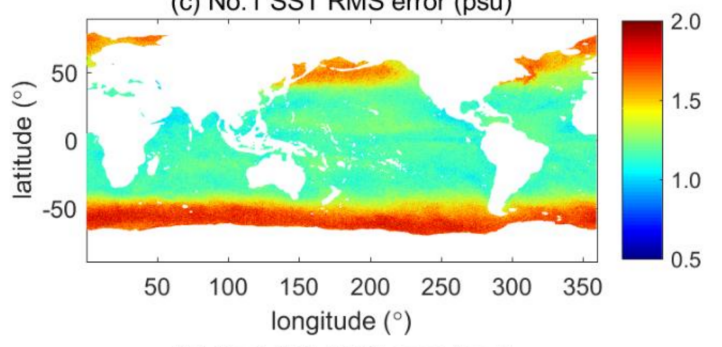

(e) No.1 WS RMS error (psu)

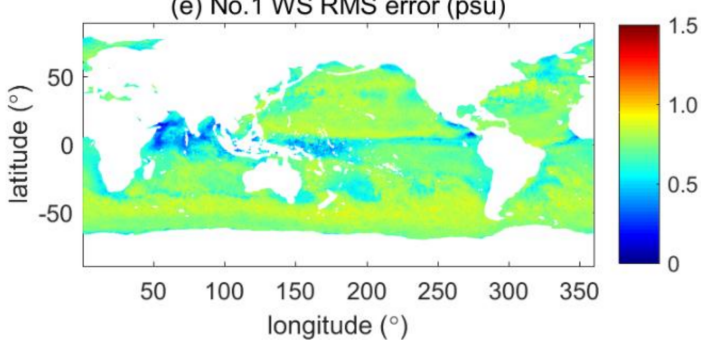

(b) No.2 SSS RMS error (psu)

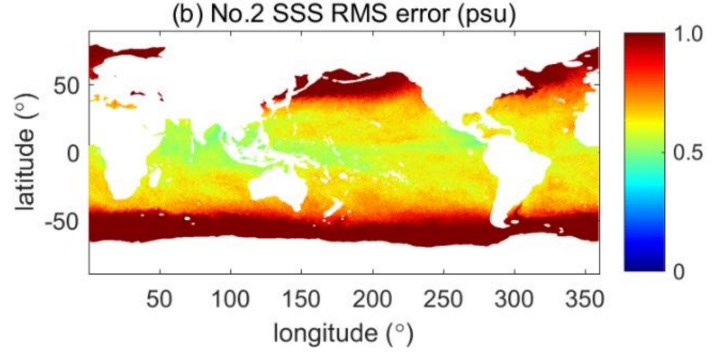

(d) No.2 SST RMS error (psu)

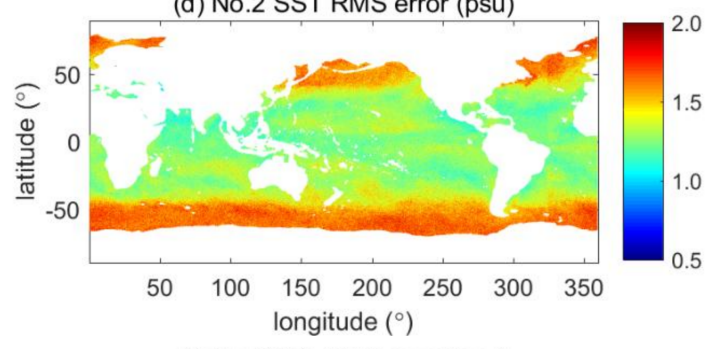

(f) No.2 WS RMS error (psu)

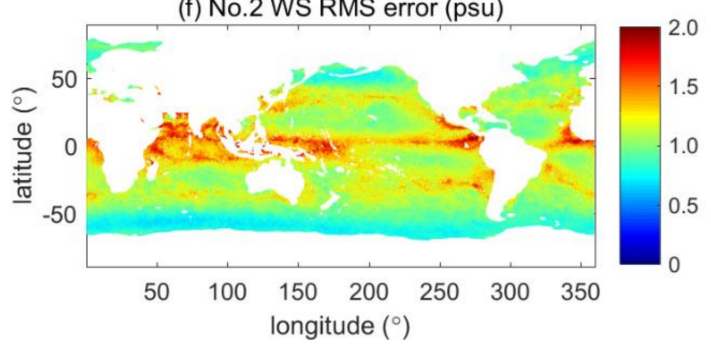

Figure 5. The errors on the retrieved SSS, SST, and WS with default configuration and with default configuration except the $1.26 \mathrm{GHz}$ scatterometer of MICAP during only one satellite pass: SSS (a); SST (c); and WS (e) errors with No. 1 configuration; and SSS (b); SST (d); and WS (f) errors with No. 2 configuration.

The SST RMS errors with No. 2 configuration vary around $1.29^{\circ} \mathrm{C}$ at the middle/low latitudes (from $50^{\circ} \mathrm{S}$ to $40^{\circ} \mathrm{N}$ ) in Figure $5 \mathrm{~d}$, and they may exceed $1.5^{\circ} \mathrm{C}$ in some regions. At most of the middle/low latitudes and high latitudes of the Northern Hemisphere, the SST RMS errors with No. 2 configuration are greater than those with No. 1. Conversely, the SST RMS errors are smaller at high latitudes of the Southern Hemisphere (above $50^{\circ} \mathrm{S}$ ).

The WS RMS error with No. 2 configuration is shown in Figure 5f. Several interesting results can be seen. The WS RMS errors are greater at middle/low latitudes (around $1.17 \mathrm{~m} / \mathrm{s}$ ) than those at high latitudes, and they even exceed $2 \mathrm{~m} / \mathrm{s}$ in low WS regions (below $3 \mathrm{~m} / \mathrm{s}$ ). Conversely, the WS RMS errors are relatively smaller in high WS regions (above $12 \mathrm{~m} / \mathrm{s}$ ). Compared to No. 1 and 
No. 3 configurations, the WS RMS errors with No. 2 increase significantly over the globe except the south of $52^{\circ} \mathrm{S}$. Especially near the equator, the WS RMS errors increase by about $0.78 \mathrm{~m} / \mathrm{s}$.

Figure 5 shows that the SSS, SST, and WS RMS errors with No. 2 configuration are greater than those with No. 1 and No. 3. Near the equator, an opposite variation tendency for WS RMS error with No. 2 configuration is observed compared with No. 1 and No. 3. Because the signal to noise ratio of high WS is higher than that of the low WS under the same noise level, the effect of noise on high WS is relatively smaller than low WS. Accordingly, the error on the retrieved WS is small at high WS.

To further analyze the influence of different instrument configurations on MICAP retrieved parameters at the middle/low latitudes, the latitudinal profiles (from $50^{\circ} \mathrm{S}$ to $40^{\circ} \mathrm{N}$ ) of SSS, SST, and WS RMS errors are shown in Figure 6. It clearly shows that the differences of the latitudinal profiles of SSS, SST, and WS RMS errors between No. 1 and No. 3 configurations are the smallest near the equator. From $10^{\circ} \mathrm{N}$ to $20^{\circ} \mathrm{N}$, the differences between No. 1 and No. 3 are the greatest due to the rapidly increasing wind speed, but still less than $0.02 \mathrm{psu}, 0.03{ }^{\circ} \mathrm{C}$ and $0.05 \mathrm{~m} / \mathrm{s}$, respectively. It indicates that there is little impact on the SSS, SST and WS RMS errors without the $23.8 \mathrm{GHz}$, which is consistent with above conclusion. Conversely, the differences between No. 1 and No. 2 configurations are the greatest near the equator (about $0.78 \mathrm{~m} / \mathrm{s}$ ) where the wind speed is lower than $3 \mathrm{~m} / \mathrm{s}$. The differences between No. 1 and No. 2 decrease gradually with increasing latitude in the Southern Hemisphere. From $40^{\circ} \mathrm{S}$ to $40^{\circ} \mathrm{N}$, the differences between No. 1 and No. 2 (average about $0.08 \mathrm{psu}, 0.1^{\circ} \mathrm{C}$ and $0.45 \mathrm{~m} / \mathrm{s}$ for SSS, SST and WS, respectively) are greater than those between No. 1 and No. 3 (average about $0.005 \mathrm{psu}, 0.01{ }^{\circ} \mathrm{C}$ and $0.03 \mathrm{~m} / \mathrm{s}$ for SSS, SST and WS, respectively). Moreover, the WS RMS error with No. 2 shows the obvious reverse change trend compared with No. 1 and No. 3. It further illustrates that it is necessary to correct the sea surface roughness using the scatterometer.

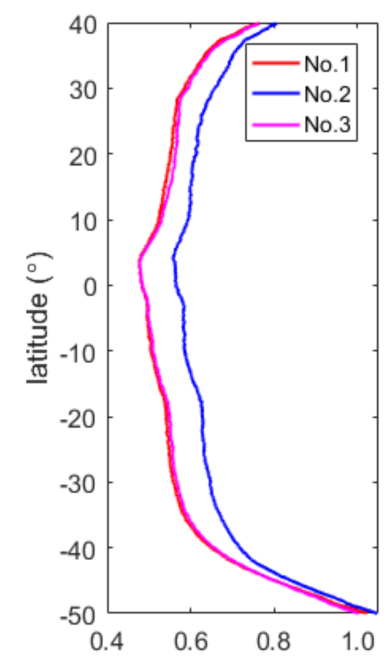

(a) SSS RMS (psu)

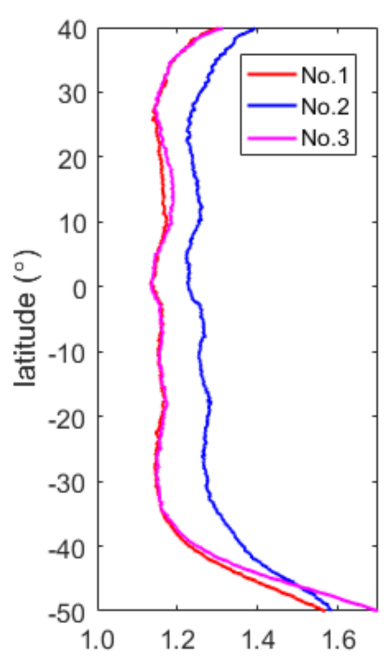

(b) SST RMS $\left({ }^{\circ} \mathrm{C}\right)$

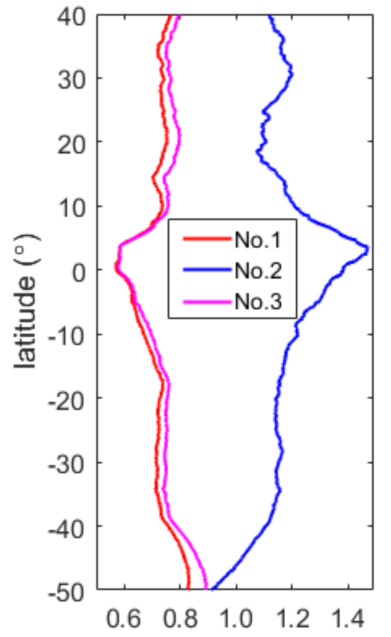

(c) WS RMS $(\mathrm{m} / \mathrm{s})$

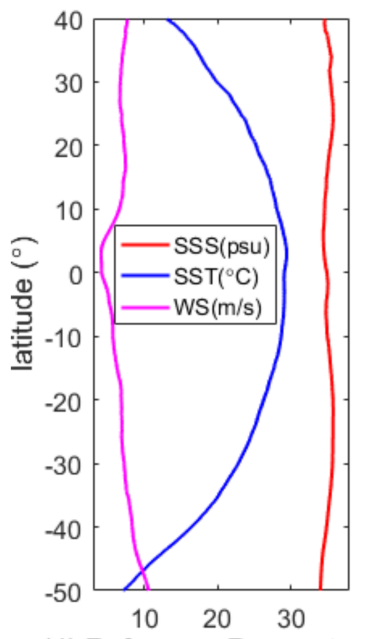

(d) Reference Parameters

Figure 6. The latitudinal profiles of the errors on the retrieved: SSS (a); SST (b); and WS (c) of MICAP; and the initialized oceanic inputs (d). The SSS, SST, and WS errors are denoted by the red, magenta and blue solid line, respectively. The horizontal coordinate of (d) represents the range of SSS (red), SST (magenta), and WS (blue).

\section{Conclusions}

In contrast to the SMOS and Aquarius, MICAP uses \multi-frequency $(1.4 \mathrm{GHz}, 6.9 \mathrm{GHz}$, 18.7 $\mathrm{GHz}$ and $23.8 \mathrm{GHz}$ ) radiometers combined with the $1.26 \mathrm{GHz}$ scatterometer to measure SSS, SST, and WS. In this paper, to further simply the instrument configuration of MICAP without loss of the SSS, SST, and WS retrieval accuracies, three different configurations (see Table 2) are compared.

From $40^{\circ} \mathrm{S}$ to $40^{\circ} \mathrm{N}$, the average differences of the latitudinal profiles of SSS, SST, and WS RMS errors between No. 1 and No. 3 configurations are about $0.005 \mathrm{psu}, 0.01{ }^{\circ} \mathrm{C}$ and $0.03 \mathrm{~m} / \mathrm{s}$, respectively. 
It indicates that No. 3 configuration also could satisfy the accuracy requirements well for global SSS, SST and WS retrievals during only one satellite pass. Thus, the instrument configuration of MICAP can be simplified (without the $23.8 \mathrm{GHz}$ channel) in the future.

By contrast, from $40^{\circ} \mathrm{S}$ to $40^{\circ} \mathrm{N}$, the average differences of the latitudinal profiles of SSS, SST, and WS RMS errors between No. 1 and No. 2 configurations are about $0.08 \mathrm{psu}, 0.1{ }^{\circ} \mathrm{C}$ and $0.45 \mathrm{~m} / \mathrm{s}$, respectively. Moreover, there are two interesting results for WS RMS error. The WS RMS error with No. 2 shows the obvious reverse change trend compared with No. 1 and No. 3. From $10^{\circ} \mathrm{S}$ to $10^{\circ} \mathrm{N}$, the differences of the latitudinal profiles of WS RMS error between No. 1 and No. 2 are up to $0.78 \mathrm{~m} / \mathrm{s}$ when the WS is lower than $5 \mathrm{~m} / \mathrm{s}$. The results indicate that the $1.26 \mathrm{GHz}$ scatterometer of MICAP is necessary for more accurate SSS, SST, and WS retrievals.

In addition, the SSS, SST, and WS RMS errors are also tested for various noise levels on their first guess values. The results indicate that the retrieval accuracies of SSS, SST, and WS are only affected by the noises added to each first guess values, which may be because the MICAP can simultaneously retrieve SSS, SST, and WS.

Acknowledgments: The authors would like to thank Laboratoire de Physique des Oceans for providing the SSS data, as well as Remote Sensing Systems for providing the initialized oceanic and atmospheric data. This work was supported by the National Key Research and Development Program of China under Grant No. 2016 YFC1401006.

Author Contributions: Xiaobin Yin conceived and established simulation models; Lanjie Zhang performed the simulate and test; Lanjie Zhang and Zhenzhan Wang analyzed test results of performance for MICAP; Lanjie Zhang wrote the manuscripts; and Zhenzhan Wang and Xiaobin Yin edited the article.

Conflicts of Interest: The authors declare no conflict of interest. The founding sponsors had no role in the design of the study; in the collection, analyses, or interpretation of data; in the writing of the manuscript, and in the decision to publish the results.

\section{References}

1. Batteen, M.L.; Collins, C.A.; Gunderson, C.R.; Nelson, C.S. The effect of salinity on density in the California Current System. J. Geophys. Res. Oceans 1995, 100, 8733-8749. [CrossRef]

2. Emery, W.J.; Meincke, J. Global water masses-summary and review. Oceanol. Acta 1986, 9, 383-391.

3. Lagerloef, G.S.; Swift, C.T.; Le Vine, D.M. Sea surface salinity: The next remote sensing challenge. Oceanography 1995, 8, 44-50. [CrossRef]

4. Schmitt, R.W. The ocean freshwater cycle. In JSC Ocean Observing System Development Panel; Texas A \& M University: College Station, TX, USA, 1994.

5. Reul, N.; Fournier, S.; Boutin, J.; Hernandez, O.; Maes, C.; Chapron, B.; Alory, G.; Quilfen, Y.; Tenerelli, J.; Morisset, S.; et al. Sea surface salinity observations from space with the SMOS satellite: A new means to monitor the marine branch of the water cycle. Surv. Geophys. 2014, 35, 681-722. [CrossRef]

6. Schmitt, R.W. Salinity and the global water cycle. Oceanography 2008, 21, 12-19. [CrossRef]

7. Font, J.; Boutin, J.; Reul, N.; Spurgeon, P.; Ballabrera-Poy, J.; Chuprin, A.; Gabarró, C.; Gourrion, J.; Guimbard, S.; Hénocq, C.; et al. SMOS first data analysis for sea surface salinity determination. Int. J. Remote Sens. 2013, 34, 3654-3670. [CrossRef]

8. Lagerloef, G.; Boutin, J.; Chao, Y.; Delcroix, T.; Font, J.; Niiler, P.; Reul, N.; Riser, S.J.; Schmitt, R.; Stammer, D.; et al. Resolving the global surface salinity field and variations by blending satellite and in situ observations. In OceanObs 09; European Space Agency: Paris, France, 2010; pp. 587-597.

9. Le Vine, D.M.; Lagerloef, G.S.; Colomb, F.R.; Yueh, S.H.; Pellerano, F.A. Aquarius: An instrument to monitor sea surface salinity from space. IEEE Trans. Geosci. Remote Sens. 2007, 45, 2040-2050. [CrossRef]

10. Boutin, J.; Martin, N.; Yin, X.B.; Font, J.; Reul, N.; Spurgeon, P. First assessment of SMOS data over Open Ocean: Part II—Sea surface salinity. IEEE Trans. Geosci. Remote Sens. 2012, 50, 1662-1675. [CrossRef]

11. Kerr, Y.H.; Waldteufel, P.; Wigneron, J.P.; Martinuzzi, J.A.M.J.; Font, J.; Berger, M. Soil moisture retrieval from space: The Soil Moisture and Ocean Salinity (SMOS) mission. IEEE Trans. Geosci. Remote Sens. 2001, 39, 1729-1735. [CrossRef]

12. Sabia, R. Sea Surface Salinity Retrieval Error Budget within the Esa Soil Moisture and Ocean Salinity Mission; Universitat Politècnica de Catalunya: Barcelona, Spain, 2008. 
13. Font, J.; Lagerloef, G.S.; Le Vine, D.M.; Camps, A.; Zanife, O.Z. The determination of surface salinity with the European SMOS space mission. IEEE Trans. Geosci. Remote Sens. 2004, 42, 2196-2205. [CrossRef]

14. Lagerloef, G.; Colomb, F.R.; Le Vine, D.; Wentz, F.; Yueh, S.; Ruf, C.; Lilly, J.; Gunn, J.; Chao, Y.; Decharon, A.; et al. The Aquarius/SAC-D mission: Designed to meet the salinity remote-sensing challenge. Oceanography 2008, 21, 68-81. [CrossRef]

15. Entekhabi, D.; Njoku, E.G.; O’Neill, P.E.; Kellogg, K.H.; Crow, W.T.; Edelstein, W.N.; Kimball, J. The soil moisture active passive (SMAP) mission. Proc. IEEE 2010, 98, 704-716. [CrossRef]

16. Le Vine, D.M.; Lagerloef, G.S.; Torrusio, S.E. Aquarius and remote sensing of sea surface salinity from space. Proc. IEEE 2010, 98, 688-703. [CrossRef]

17. Fore, A.G.; Yueh, S.H.; Tang, W.; Stiles, B.W.; Hayashi, A.K. Combined Active/Passive Retrievals of Ocean Vector Wind and Sea Surface Salinity with SMAP. IEEE Trans. Geosci. Remote Sens. 2016, 54, 7396-7404. [CrossRef]

18. Akhil, V.P.; Lengaigne, M.; Durand, F.; Vialard, J.; Chaitanya, A.V.S.; Keerthi, M.G.; Gopalakrishna, V.V.; Boutin, J.; de Boyer Montégut, C. Assessment of seasonal and year-to-year surface salinity signals retrieved from SMOS and Aquarius missions in the Bay of Bengal. Int. J. Remote Sens. 2016, 37, 1089-1114. [CrossRef]

19. Philipps, S.; Boone, C.; Obligis, E. The role of averaging for improving sea surface salinity retrieval from the Soil Moisture and Ocean Salinity (SMOS) satellite and impact of auxiliary data. J. Atmos. Ocean. Technol. 2007, 24, 255-269. [CrossRef]

20. Yueh, S.H.; West, R.; Wilson, W.J.; Li, F.K.; Njoku, E.G.; Rahmat-Samii, Y. Error sources and feasibility for microwave remote sensing of ocean surface salinity. IEEE Trans. Geosci. Remote Sens. 2001, 39, 1049-1060. [CrossRef]

21. Zhang, L.J.; Yin, X.; Wang, Z.Z.; Liu, H.; Lin, M.S. Preliminary Analysis of the Potential and Limitations of MICAP for the Retrieval of Sea Surface Salinity. IEEE J. Sel. Top. Appl. Earth Observ. Remote Sens. 2018, submitted.

22. Gaillard, F. ISAS-13 temperature and salinity gridded fields. SEANOE 2015. [CrossRef]

23. Wentz, F.J.; Ricciardulli, L.; Gentemann, C.; Meissner, T.; Hilburn, K.A.; Scott, J. Remote Sensing Systems GCOM-W1 AMSR2 Monthly Environmental Suite on 0.25 Deg Grid, Version 7.0; Remote Sensing Systems: Santa Rosa, CA, USA, 2014; Available online: www.remss.com/missions/amsr (accessed on 1 March 2017).

24. Wentz, F.J.; Ricciardulli, L.; Gentemann, C.; Meissner, T.; Hilburn, K.A.; Scott, J. Remote Sensing Systems Coriolis WindSat Monthly Environmental Suite on 0.25 Deg Grid, Version 7.0.1; Remote Sensing Systems: Santa Rosa, CA, USA, 2013; Available online: www.remss.com/missions/windsat (accessed on 2 March 2017).

25. Font, J.; Camps, A.; Borges, A.; Martín-Neira, M.; Boutin, J.; Reul, N.; Mecklenburg, S. SMOS: The challenging sea surface salinity measurement from space. Proc. IEEE 2010, 98, 649-665. [CrossRef]

26. Yin, X.B.; Boutin, J.; Martin, N.; Spurgeon, P.; Vergely, J.L.; Gaillard, F. Errors in SMOS Sea Surface Salinity and their dependency on a priori wind speed. Remote Sens. Environ. 2014, 146, 159-171. [CrossRef]

27. Revision 13 SMOS L2 OS Algorithm Theoretical Baseline Document, SO-TN-ARG-GS-0007. Available online: http:/ / www.argans.co.uk/smos/docs/deliverables/delivered/ATBD/SO-TN-ARG-GS-007_L2OSATBD_v3.7_110622.pdf. (accessed on 13 March 2017).

28. Meissner, T.; Wentz, F.J.; Ricciardulli, L. The emission and scattering of L-band microwave radiation from rough ocean surfaces and wind speed measurements from the Aquarius sensor. J. Geophys. Res. Oceans 2014, 119, 6499-6522. [CrossRef]

29. Dinnat, E.P.; Boutin, J.; Yin, X.; Le Vine, D.M.; Waldteufel, P.; Vergely, J.L. Comparison of SMOS and Aquarius Sea Surface Salinity and analysis of possible causes for the differences. In Proceedings of the XXXIth URSI IEEE General Assembly and Scientific Symposium (URSI GASS), Beijing, China, 16-23 August 2014.

30. Klein, L.; Swift, C. An improved model for the dielectric constant of sea water at microwave frequencies. IEEE J. Ocean. Eng. 1977, 2, 104-111. [CrossRef]

31. Meissner, T.; Wentz, F.J. The emissivity of the ocean surface between 6 and $90 \mathrm{GHz}$ over a large range of wind speeds and earth incidence angles. IEEE Trans. Geosci. Remote Sens. 2012, 50, 3004-3026. [CrossRef]

32. Zhou, Y.; Lang, R.H.; Dinnat, E.P.; Le Vine, D.M. L-Band Model Function of the Dielectric Constant of Seawater. IEEE Trans. Geosci. Remote Sens. 2017, 55, 6964-6974. [CrossRef]

33. Zine, S.; Boutin, J.; Font, J.; Reul, N.; Waldteufel, P.; Gabarró, C.; Delwart, S. Overview of the SMOS sea surface salinity prototype processor. IEEE Trans. Geosci. Remote Sens. 2008, 46, 621-645. [CrossRef] 
34. Yin, X.B.; Boutin, J.; Martin, N.; Spurgeon, P. Optimization of L-band sea surface emissivity models deduced from SMOS data. IEEE Trans. Geosci. Remote Sens. 2012, 50, 1414-1426. [CrossRef]

35. Liebe, H.J.; Hufford, G.A.; Cotton, M.G. Propagation modeling of moist air and suspended water/ice particles at frequencies below $1000 \mathrm{GHz}$. In Proceedings of the AGARD 52nd Specialists' Meeting Electromagnetic Wave Propagation Panel, Palma de Mallorca, Spain, May 1993.

36. Wentz, F.J.; Meissner, T. Algorithm Theoretical Basis Document (atbd), Version 2; RSS Tech. Proposal 121599A-1; Remote Sensing Systems: Santa Rosa, CA, USA, 2000.

37. Isoguchi, O.; Shimada, M. An L-band ocean geophysical model function derived from PALSAR. IEEE Trans. Geosci. Remote Sens. 2009, 47, 1925-1936. [CrossRef]

38. Liu, H.; Zhu, D.; Niu, L.; Wu, L.; Wang, C.; Chen, X.; Wu, J. MICAP (Microwave imager combined active and passive): A new instrument for Chinese ocean salinity satellite. In Proceedings of the 2015 IEEE International Geoscience and Remote Sensing Symposium (IGARSS), Milan, Italy, 26-31 July 2015; pp. 184-187.

2018 by the authors. Licensee MDPI, Basel, Switzerland. This article is an open access article distributed under the terms and conditions of the Creative Commons Attribution (CC BY) license (http://creativecommons.org/licenses/by/4.0/). 